\title{
Course and characteristics of anaemia in patients with rheumatoid arthritis of recent onset
}

H R M Peeters, M Jongen-Lavrencic, A N Raja, H S Ramdin, G Vreugdenhil, F C Breedveld, A J G Swaak

\begin{abstract}
Objective-To describe the incidence, cause, and course of anaemia in rheumatoid arthritis (RA).

Methods-Medical records of 225 patients who received a diagnosis of RA between 1990 and 1992 were reviewed longitudinally for mention of anaemia. Anaemia was classified as anaemia of chronic disease if ferritin concentrations reflected adequate body iron stores. Among iron depleted anaemic patients, iron deficiency anaemia was identified using the response to iron supplementation.
\end{abstract}

Results-Anaemia developed in $64 \%$ of the patients, mostly within 18 months of follow up, but disappeared again in $54 \%$ of those patients. The prevalence of anaemia varied from $39 \%$ to $53 \%$ throughout follow up. Iron depletion was found in $38 \%$ of anaemic patients; $40 \%$ of them did not recover from their anaemia after iron supplementation and were classified as having anaemia of chronic disease. Anaemia of chronic disease thus caused $77 \%$ and iron deficiency anaemia $23 \%$ of observed anaemia. Recovery from anaemia occurred in $42 \%$ of the patients with anaemia of chronic disease and in $72 \%$ of iron depleted patients after iron supplementation. Anaemic patients, particularly those with anaemia of chronic disease, had a significantly greater number of the American College of Rheumatism criteria for RA, significantly more erosive joint damage, and significantly increased concentrations of serum rheumatoid factor than patients without anaemia.

Conclusion-Anaemia appeared as a frequent and dynamic manifestation. Recovery and recurrence of anaemia was observed throughout follow up, leading to a longstanding and relatively high prevalence of the condition. Iron deficiency was diagnosed frequently and follow up revealed a considerable overlap with anaemia of chronic disease, making this the most important cause of anaemia in RA. Recovery from anaemia occurred more frequently in iron depleted anaemic patients than in those with anaemia of chronic disease. Anaemic patients, particularly those with anaemia of chronic disease, seemed to have a more serious course of their RA compared with nonanaemic patients.

(Ann Rheum Dis 1996; 55: 162-168)
Anaemia is a frequently occurring extraarticular manifestation in patients with rheumatoid arthritis (RA). Anaemia of chronic disease and iron deficiency anaemia are considered to be the most important causes. ${ }^{1-3}$ The prevalence of anaemia in RA was found to range from $30 \%$ to $70 \%$ in cross sectional studies. ${ }^{14-6}$ Anaemia of chronic disease, usually distinguished from iron deficiency anaemia by the evaluation of body iron stores, was found in the majority of patients. However, as the diagnosis iron deficiency anaemia can only be confirmed by the results of supplementation with iron, ${ }^{7-9}$ it is not clear to what extent anaemia of chronic disease and iron deficiency can simultaneously have a role in the development of the anaemia. ${ }^{4}$

Anaemia of chronic disease can be regarded as the result of current inflammation, and has been found to be associated with greater disease activity of RA. ${ }^{10-14}$ Although anaemia of chronic disease in general was described as mild and reversible, ${ }^{13}$ the long term outcome of anaemia of chronic disease in a large population of patients with RA has not been studied. Iron deficiency has been observed frequently in anaemic patients with RA: thus $\mathrm{RA}$ and the treatment of RA may be risk factors for a negative iron balance. ${ }^{15}$ However, the frequency of iron deficiency and its relation with iron deficiency anaemia has not been studied in detail.

Recently, our department has been involved in extensive research on the pathogenesis, diagnosis, and treatment of anaemia in patients with RA. ${ }^{2916}$ As a result, there is an active policy towards diagnosis and treatment of anaemia in the patients with RA who are treated in the department. This has enabled us to investigate the incidence of anaemia in RA by conducting a retrospective longitudinal study in a population of patients with recent onset of the disease. After distinguishing iron deficiency anaemia from anaemia of chronic disease by the effect of iron supplementation treatment in iron depleted anaemic patients, we documented the course of both types of anaemia and disease, and the demographic characteristics of the different anaemic groups.

\section{Patients and methods}

PATIENTS

Medical records of 3126 patients who were referred for the first time to the outpatient clinic of our department of rheumatology between January 1990 and July 1992 were 
reviewed in 1993. Patients were included in the study if they fulfilled the revised American College of Rheumatology (ACR) criteria for $\mathrm{RA}^{17}$ and if the diagnosis was first made by one of the rheumatologists from the department; in this way 262 records were selected. To enable us to study the course of anaemia in individual patients, a minimum follow up of six months was arbitrarily required. Exclusion of 37 patients with less than six months follow up finally resulted in a cohort of 225 patients.

\section{ASSESSMENTS}

Demographic data - Gender, age at onset of RA, duration of follow up, and the time of onset of anaemia were retrieved from the records.

Disease characteristics-For all patients we recorded the number of ACR criteria for RA, the total number of prescribed disease modifying antirheumatic drugs (DMARDs), and the use of non-steroidal anti-inflammatory drugs (NSAIDs), DMARDs, or oral corticosteroids during the study. In all but one patient, serum rheumatoid factor titres were recorded (Waaler-Rose test); a titre of $>32$ was considered positive. Antinuclear factors (ANF) were assessed in a qualitative manner by means of an immunofluorescence test in 214 patients. For 201 patients, radiographs of the hand and feet were available, and were reviewed for the presence of erosive joint damage.

Data on anaemia-The haemoglobin concentrations at three month intervals were abstracted from the records; overall, these data were available for $81 \%$ of all reviewed time points. Anaemia was defined by the presence of two or more consecutive haemoglobin measurements that were less than the normal values (which are $>7.4 \mathrm{mmol} / \mathrm{l}$ for women and $>8.5 \mathrm{mmol} / \mathrm{l}$ for men). ${ }^{16}{ }^{18}$ Patients who did not develop anaemia were designated group 1 . For all the patients who did develop anaemia (group 2), the following details about its course were collected: time between first visit and development of anaemia, minimum haemoglobin concentration, recovery of anaemia, time to recovery, number of distinct episodes of anaemia.

Classification of chronic anaemia-Figure 1 shows the stepwise identification of the different subgroups within the population.

Serum concentrations of ferritin measured in anaemic patients were used to distinguish between iron deficient anaemic patients (group $3=$ ferritin $<50 \mu \mathrm{g} / \mathrm{l}$ ) and those anaemic patients with adequate body stores of iron (group $4=$ ferritin $>50 \mu \mathrm{g} / \mathrm{l}$ )..$^{161920} \mathrm{In}$ 30 patients in group 2, no ferritin measurements were available and this anaemia was retrospectively considered to be not classifiable.

In our department, iron deficient anaemic patients are treated initially with oral iron supplementation for three months. If a normalisation of ferritin concentrations does not occur in this period, patients are then treated with parenteral iron supplements until

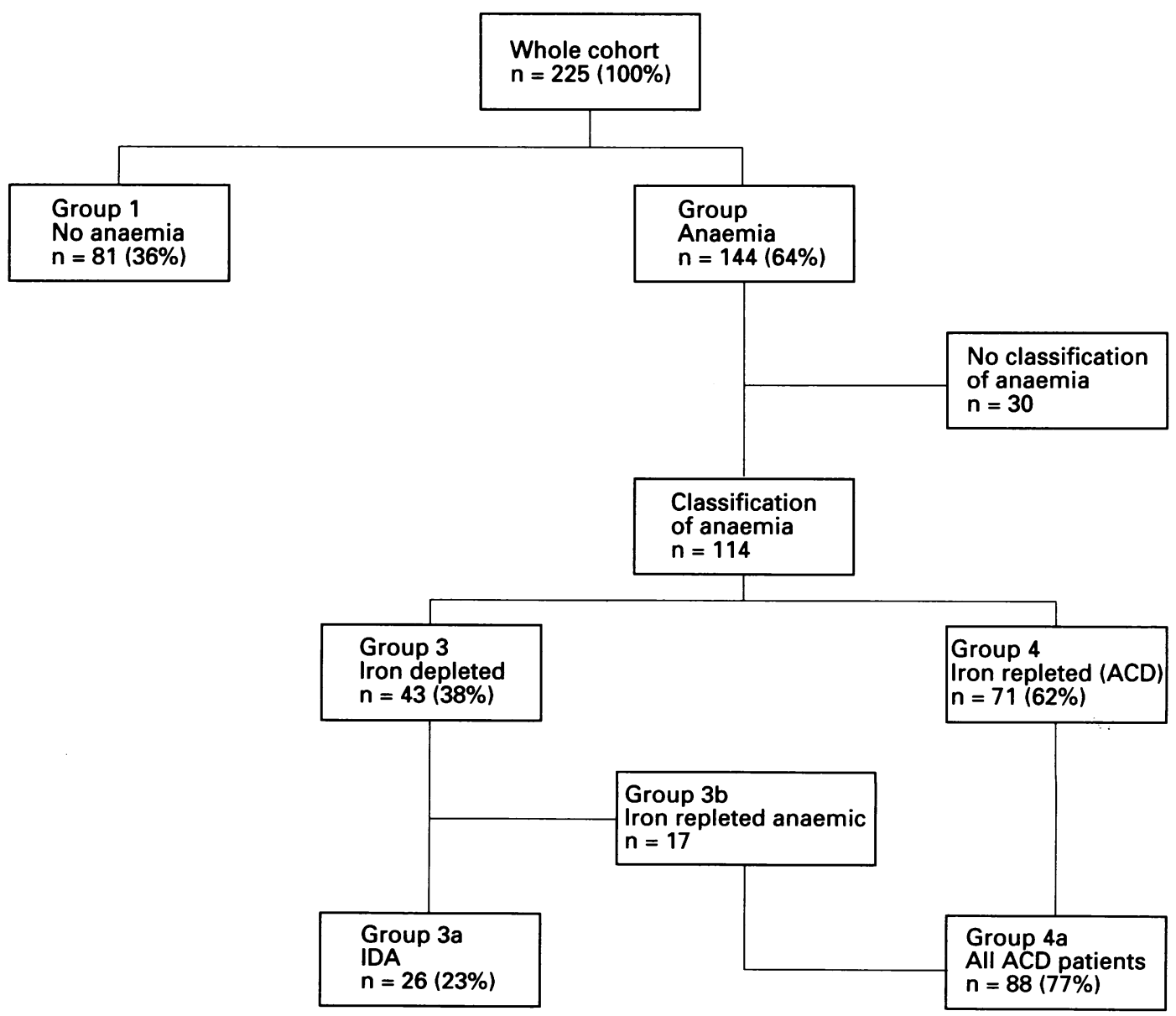

Figure 1 Classification of the patients according to the presence and cause of anaemia. ACD = Anaemia of chronic disease; IDA = iron deficiency anaemia. 
the concentrations do normalise. A significant haematological response has been defined as normalisation of haemoglobin concentrations with an increase of at least $1 \mathrm{mmol} / .^{7-9}$ The effect of this treatment in the iron depleted anaemic patients was evaluated to differentiate further the iron deficient patients in group 3: group 3a comprised those patients who achieved normal concentrations of haemoglobin and ferritin, thus fulfilling the criterion for iron deficiency anaemia, while group $3 b$ comprised those iron depleted patients who remained anaemic despite repletion of their body iron stores, thus fulfilling the criterion for anaemia of chronic disease. The anaemic patients of group 4 and group $3 \mathrm{~b}$ formed the complete cohort of patients with anaemia of chronic disease (group 4a).

\section{STATISTICAL PROCEDURES}

The data were stored in a personal computer using a spreadsheet program (Lotus123, version $1 \cdot 3)$. Basic statistical analyses were performed in the Stata statistical program, version $3 \cdot 1$.

Between group differences of continuous variables were analysed using Student's $t$ test for unpaired data (normally distributed) or the Mann-Whitney $U$ test for non-parametrically distributed data. Categorical or dichotomous data were analysed by $\chi^{2}$ test or Fisher's exact test where appropriate. For the comparison of subsets of patients, the Bonferroni method was used to correct the level of significance for multiple comparisons. Kaplan-Meier estimates were used to estimate the probabilities of development of and recovery from anaemia during follow up for all patients and for the individual groups; between group differences were analysed using the log rank test. The course of changes in median haemoglobin concentrations and prevalence of anaemia in all patients and the individual groups were tested for overall between groups and time effects by analysis of variance for repeated measurements (Manova, SPSS/PC 5.01) in the case of haemoglobin, and by logistic regression with random effects (Egret) in the case of the prevalence of anaemia.

\section{Results}

DEMOGRAPHIC AND DISEASE CHARACTERISTICS OF ALL PATIENTS

The first column of table 1 shows the characteristics of all 225 patients. Onset of arthritic symptoms occurred a median of five months (range 1-60) before the patient's first visit to the outpatient clinic. The duration of follow up was a median 24 months (range 6-36). During follow up all 225 patients took NSAIDs, while $68 \%$ received DMARDs and $21 \%$ received oral corticosteroids in addition.

\section{CLASSIFICATION OF ANAEMIA}

Anaemia occurred in $144(64 \%)$ of patients (group 2): classification of their anaemia was possible for 114 of them (fig 1, table 1). Among those classifiable patients, $38 \% \quad(46 \%$ of women and $18 \%$ of men) initially had depleted body stores of iron (group 3) and $62 \%$ had adequate stores (group 4). After iron supplementation, $26(60 \%)$ of the patients within group 3 became iron repleted and nonanaemic, thereby fulfilling the criterion for iron deficiency anaemia (group 3a), whereas 17 $(40 \%)$ remained anaemic despite normalisation of body iron stores and were classified as having anaemia of chronic disease (group $3 \mathrm{~b}$ ). Thus $23 \%$ of anaemic patients were classified as having iron deficiency anaemia and $77 \%$ as having anaemia of chronic disease. Overall, therefore, iron deficiency anaemia occurred in $15 \%(17 \%$ of women and $8 \%$ of men) and anaemia of chronic disease occurred in $49 \%$ ( $41 \%$ of women and $68 \%$ of men) of all 225 patients with RA.

DEMOGRAPHIC AND DISEASE CHARACTERISTICS OF THE DIFFERENT GROUPS

Comparison of the demographic and disease variables of the individual groups revealed no differences in the time between onset of symptoms and study entry, or in duration of follow up between the groups (data not shown). Anaemic patients (group 2) were more often male, had more erosive joint damage, had a greater number of ACR criteria, were more

Table 1 Demographic and disease characteristics of patients with rheumatoid arthritis studied for anaemia

\begin{tabular}{|c|c|c|c|c|c|c|c|c|}
\hline & \multirow{2}{*}{$\begin{array}{l}\text { All } \\
(n=225)\end{array}$} & \multicolumn{2}{|c|}{ Non-anaemic $\mathrm{v}$ anaemic } & \multicolumn{2}{|c|}{ First classification anaemia } & \multicolumn{3}{|c|}{ Classification after follow up } \\
\hline & & $\begin{array}{l}\text { Group 1 } \\
(n=81)\end{array}$ & $\begin{array}{l}\text { Group 2 } \\
(n=144)\end{array}$ & $\begin{array}{l}\text { Group } 3 \\
(n=43)\end{array}$ & $\begin{array}{l}\text { Group 4 } \\
(n=71)\end{array}$ & $\begin{array}{l}\text { Group } 3 a \\
(n=26)\end{array}$ & $\begin{array}{l}\text { Group } 3 b \\
(n=17)\end{array}$ & $\begin{array}{l}\text { Group } 4 a \\
(n=88)\end{array}$ \\
\hline $\begin{array}{l}\text { Sex (female) } \\
\text { Age (years) } \\
\text { Erosive disease } \\
\text { Positive rheumatoid factor } \\
\text { Positive ANF } \\
>5 \text { ACR criteria } \\
\text { Number of DMARDs }\end{array}$ & $\begin{array}{l}152(67) \\
61(21-84) \\
139(65) \\
100(45) \\
31(65) \\
67(30)\end{array}$ & $\begin{array}{l}63(78) \\
59(21-83) \\
43(56) \\
28(35) \\
16(22) \\
16(20)\end{array}$ & $\begin{array}{l}89(62)^{\star} \\
63(31-85) \\
96(70)^{\star} \\
72(50)^{\star} \\
15(13) \\
51(35)^{\star}\end{array}$ & $\begin{array}{l}36(84) \dagger \\
58(21-84) \dagger \\
27(64) \\
22(51) \\
7(19) \\
18(42)^{\star}\end{array}$ & $\begin{array}{l}39(55)^{\star} \\
68(31-85)^{\star} \\
54(78)^{\star} \\
36(51) \\
6(10) \\
26(37)^{\star}\end{array}$ & $\begin{array}{l}22(85) \ddagger \\
57(23-79) \ddagger \\
15(60) \\
8(31) \ddagger \\
3(13) \\
9(35)\end{array}$ & $\begin{array}{l}14(82) \\
52(21-84) \\
12(71) \\
14(82)^{\star} \\
1(16) \\
9(53)^{\star}\end{array}$ & $\begin{array}{l}53(60)^{\star} \\
66(21-85)^{\star} \\
66(77)^{\star} \\
50(57)^{\star} \\
10(14) \\
35(40)^{\star}\end{array}$ \\
\hline $\begin{array}{r}0 \\
1 \\
>1\end{array}$ & $\begin{array}{r}72(32) \\
104(46) \\
49(22)\end{array}$ & $\begin{array}{l}30(37) \\
40(49) \\
11(14)\end{array}$ & $\begin{array}{l}42(29) \\
64(45) \\
38(26)\end{array}$ & $\begin{array}{l}14(33)^{\star} \\
13(30) \\
16(37)\end{array}$ & $\begin{array}{l}20(28) \\
37(52) \\
14(20)\end{array}$ & $\begin{array}{l}9(35) \\
9(35) \\
8(30)\end{array}$ & $\begin{array}{l}5(29) \\
4(24) \\
8(47)\end{array}$ & $\begin{array}{l}25(28) \\
41(47) \\
22(25)\end{array}$ \\
\hline $\begin{array}{l}\text { Systemic corticosteroids } \\
\text { ever used }\end{array}$ & $47(21)$ & $7(9)$ & $40(28)^{\star}$ & $13(30)^{\star}$ & $19(27)^{\star}$ & $4(15)$ & $9(53)^{\star}$ & $28(32)^{\star}$ \\
\hline
\end{tabular}

Values are absolute number (percentage) or median (range)

Group 1 = Patients without anaemia during follow up; group 2 = patients who developed anaemia; group $3=$ anaemic patients, Group $1=$ Patients without anaemia during follow up; group $2=$ patients who developed anaemia; group $3=$ anaemic patients,
who initially showed depleted body iron stores; group $4=$ anaemic patients with adequate body iron stores; group $3 \mathrm{a}=$ patients who initially showed depleted body iron stores; group $4=$ anaemic patients with adequate body iron stores; group 3a $=$ patients of group 3 who achieved normal haemoglobin concentrations and iron stores after iron supplementation (iron deficiency anaemia); group $3 \mathrm{~b}=$ patients of group 3 , who remained anaemic despite normalisation
patients fullfilling criteria for anaemia of chronic disease (groups $3 b+4$ ).

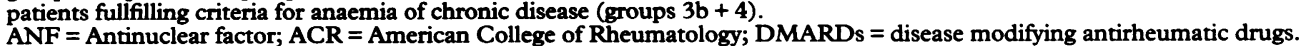
Significant differences $(p<0 \cdot 05)$ compared with: *group 1, tgroup 4; †group 4a. 
frequently positive for increased serum rheumatoid factor titre, and more frequently received systemic corticosteroid treatment, compared with non-anaemic patients (table 1).

Similar differences were apparent when patients with anaemia of chronic disease (groups 4 and $4 a$ ) were compared with patients without anaemia (group 1). All iron deficient anaemic patients (group 3) showed the same gender and age distribution as group 1; the number of ACR criteria was greater and they more often received treatment with DMARDs and corticosteroids. The patients in group $3 \mathrm{a}$ (iron deficiency anaemia) did not show any differences in demographic and disease characteristics compared with patients without anaemia, whereas those in group $3 b$ (iron deficient anaemic patients revealing anaemia of chronic disease after iron supplementation) were more often seropositive, had a greater number of ACR criteria, and received more corticosteroid treatment. Patients with iron deficiency anaemia (group 3a) were younger, more often female, and less frequently positive for rheumatoid factor compared with patients with anaemia of chronic disease (group 4a). Demographic and disease characteristics are not shown for the 30 patients in group 2 for whom classification of their anaemia was not possible because serum ferritin measurements were lacking. No differences were observed between these patients and the other 114 patients of group 2 in whom the anaemia could be classified.

DEVELOPMENT AND COURSE OF ANAEMIA Anaemia developed soon after the onset of RA; $63 \%$ of the group 2 patients were already anaemic at their first outpatient clinic visit and $93 \%$ developed their anaemia within one year of follow up. In most cases anaemia was mild,
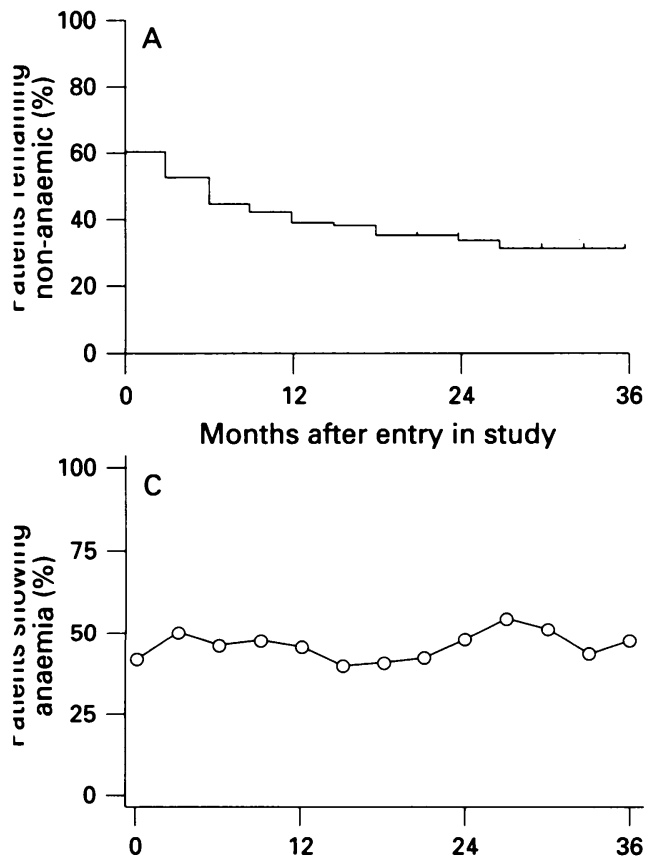

as illustrated by the median minimum haemoglobin value of $6.8 \mathrm{mmol} / \mathrm{l}$. Eighty five (59\%) of all anaemic patients recovered from anaemia before the end of follow up- $73 \%$ of them within a year after becoming anaemic. Thirteen $(9 \%)$ of all anaemic patients experienced more than one episode of anaemia during follow up. Figure 2 depicts the course of anaemia graphically. Figure $2 \mathrm{~A}$ is a Kaplan-Meier curve showing the cumulative proportion of the 225 patients with RA who did not develop anaemia during follow up. It confirms that in most patients anaemia occurs early in the course of their RA, and that after 18 months of follow up the incidence of anaemia, developing for the first time, decreases. Figure 2B shows the cumulative probability of the 144 patients of group 2 remaining anaemic during follow up: a steady decrease of the number of patients remaining anaemic in time was observed during the whole period of follow up. (It should be noted that figure $2 \mathrm{~B}$ does not show the effect of those patients who developed a second period of anaemia.) Figure 2C and 2D present the prevalence of anaemia and the median haemoglobin concentration, respectively, in all patients during follow up, summarising the net result of the described process of development, recovery, and recurrence of anaemia within the whole population. The prevalence of anaemia varies from $39 \%$ to $53 \%$, and the median haemoglobin concentration from $7 \cdot 7$ to $8 \cdot 1 \mathrm{mmol} / \mathrm{l}(7 \cdot 5-7 \cdot 8 \mathrm{mmol} / 1$ for women, and $8 \cdot 1-8.6 \mathrm{mmol} / 1$ for men). Statistical analysis showed no significant effects of time in either of these curves.

Few differences in the course of anaemia were observed (table 2) when iron depleted anaemic patients (group 3) were compared with anaemic patients with adequate stores of body iron (group 4). The same time interval between the first clinic visit and development

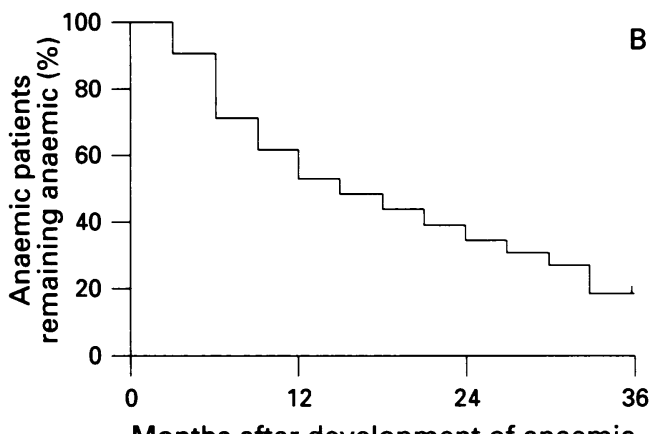

Months after development of anaemia

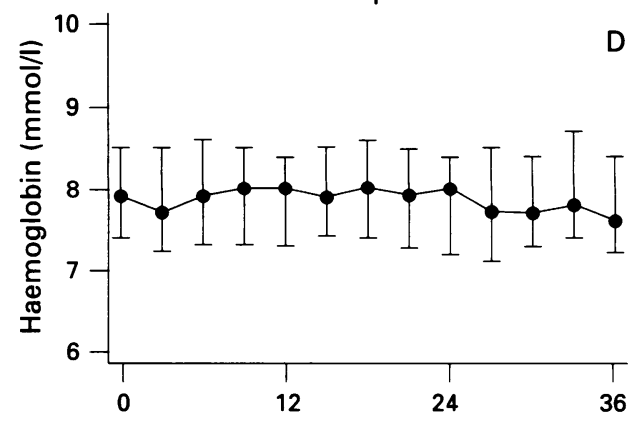

Figure 2 Incidence and course of anaemia during follow up. A: Survival function analysis (Kaplan-Meier), showing the rate of development of anaemia in the patients studied. B:Survival function analysis showing the rate of normalisation of haemoglobin concentrations in anaemic patients. C: Prevalence of anaemia during follow up. D: Time course of changes in median haemoglobin concentration (with interquartile range). 
Table 2 Characteristics of anaemia in the different groups

\begin{tabular}{|c|c|c|c|c|c|c|}
\hline & \multirow{2}{*}{$\begin{array}{l}\text { Anaemia } \\
\text { Group } 2 \\
(n=144)\end{array}$} & \multicolumn{2}{|c|}{ First classification anaemia } & \multicolumn{3}{|c|}{ Classification after follow up } \\
\hline & & $\begin{array}{l}\text { Group 3 } \\
(n=43)\end{array}$ & $\begin{array}{l}\text { Group 4 } \\
(n=71)\end{array}$ & $\begin{array}{l}\text { Group } 3 a \\
(n=26)\end{array}$ & $\begin{array}{l}\text { Group } 3 b \\
(n=17)\end{array}$ & $\begin{array}{l}\text { Group 4a } \\
(n=88)\end{array}$ \\
\hline $\begin{array}{l}\text { Time until development of anaemia } \\
\text { (months after first visit) } \\
\text { Minimum haemoglobin concn (mmol//) } \\
\text { Recovery from anaemia }\end{array}$ & $\begin{array}{l}0(0-27) \\
6 \cdot 8(4 \cdot 7-8 \cdot 4) \\
85(59)\end{array}$ & $\begin{array}{l}0(0-27) \\
6 \cdot 7(4 \cdot 7-7 \cdot 4) \\
31(72)^{\star}\end{array}$ & $\begin{array}{l}0(0-27) \\
6 \cdot 6(5 \cdot 3-8 \cdot 4) \\
30(42)\end{array}$ & $\begin{array}{l}0(0-18) \\
6 \cdot 8(4 \cdot 7-7 \cdot 4) \\
26(100)\end{array}$ & $\begin{array}{l}0(0-27) \\
6 \cdot 6(5 \cdot 6-7 \cdot 2) \\
5(29)\end{array}$ & $\begin{array}{l}0(0-27) \\
6 \cdot 6(5 \cdot 3-8 \cdot 4) \\
35(40)\end{array}$ \\
\hline $\begin{array}{l}\text { Time to recovery from anaemia } \\
\text { (months after development of anaemia) } \\
\text { More than one anaemic episode }\end{array}$ & $\begin{array}{l}11(3-36) \\
13(9)\end{array}$ & $\begin{array}{c}12(3-36) \\
5(12)\end{array}$ & $\begin{array}{c}12(3-36) \\
5(7)\end{array}$ & $\begin{array}{c}10(3-27) \\
3(11)\end{array}$ & $\begin{array}{c}18(6-36) \\
2(12)\end{array}$ & $\begin{array}{c}14(3-36) \\
7(8)\end{array}$ \\
\hline
\end{tabular}

Values are absolute numbers (percentage) or median (range)

Group definitions as in table 1 .

$\star$ Significant difference $(p<0.05)$ compared with group 4.

of anaemia was observed. There were no differences in minimum concentrations of haemoglobin. The most important difference between both groups was the greater proportion of patients who recovered from anaemia in the iron depleted group $(72 \%$ compared with $42 \%$ ). However, the time needed for this recovery did not differ significantly between the groups. Comparison of the Kaplan-Meier curves of the cumulative probabilities of development of and recovery from anaemia in both groups did not reveal statistically significant differences, indicating that within group changes in the proportions of patients developing and recovering from anaemia were comparable in both groups during follow up. Patients with iron deficiency anaemia (group 3a) had a shorter median time to recovery from anaemia than those with anaemia of chronic disease (group 4a), but this did not reach statistical significance. Among the 30 patients of group 2 with non-classifiable anaemia, more frequent $(80 \%, \mathrm{p}<0.01)$ and earlier (median six months, $p=0.02$ ) recovery from anaemia, and greater minimum concentrations of haemoglobin (median $7.4 \mathrm{mmol} / \mathrm{l}$, $\mathrm{p} \leq 0.01$ ) were observed, compared with the other patients in the group (data not shown).

\section{Discussion}

The incidence, cause, and course of anaemia were studied in patients with RA of recent onset. In the majority of the patients, the onset of symptoms of arthritis was shortly before the date of presentation. Anaemia of mild severity occurred in $64 \%$ of all patients, predominantly within the first year after onset of RA. Recovery from anaemia was observed in $59 \%$ of the anaemic patients; it was followed by recurrence of anaemia in $14 \%$. Follow up was too short to establish the precise recovery and recurrence rate of anaemia, but it can be concluded that anaemia occurred in a distinct proportion of patients with RA, in whom its recovery and recurrence continued throughout follow up. During follow up, the prevalence of anaemia varied from $39 \%$ to $53 \%$ of the 225 patients with RA.

Anaemic patients, particularly those with anaemia of chronic disease, were more often men and showed more features of a severe course of RA than patients without anaemia. Patients with iron deficiency anaemia had demographic and disease characteristics similar to those of patients without anaemia; they were younger and more often women than were patients with anaemia of chronic disease.

At the initial classification of their anaemia, $38 \%$ of the anaemic patients showed depleted body iron stores. Within the iron depleted group, after iron supplementation $60 \%$ eventually fulfilled the criterion for iron deficiency anaemia, but $40 \%$ remained anaemic despite repletion of body iron stores and were therefore classified as having anaemia of chronic disease. Overall, anaemia was classified as anaemia of chronic disease in $77 \%$ and as iron deficiency anaemia in $23 \%$ of the anaemic patients; these patients represented $49 \%$ and $15 \%$, respectively, of the entire cohort of 225 patients with RA. A greater proportion of iron depleted anaemic patients recovered from their anaemia compared with the anaemic patients with apparently adequate body stores of iron (72\% $v 40 \%$ ), but there were no other differences between groups regarding time of onset of anaemia, cumulative probability of developing anaemia, and minimum haemoglobin concentrations. While our findings from the initial classification of anaemia are in agreement with those of previous studies, ${ }^{148}$ our follow up of the iron depleted anaemic patients in the present study has now demonstrated in addition that, in a considerable proportion of these patients, the anaemia was caused by the presence of chronic disease.

The observed prevalence of predominantly mild anaemia is compatible with the findings of previous cross sectional studies. ${ }^{1-3} 13$ What the present study has demonstrated is that the anaemia recurs frequently, leading to a longstanding and relatively high prevalence of anaemia in the population of patients with $R A$ studied.

It should be noted that the diagnosis of iron deficiency by means of iron staining of a bone marrow aspirate was not an available option in the present study, as a bone marrow aspirate was not performed. Measurement of serum concentrations of ferritin has proved to be the most suitable alternative marker for iron status, but it cannot identify (or exclude) all cases of iron deficiency. Nevertheless, threshold values of $50-60 \mu \mathrm{g} / 1$ have been shown to correspond with a validity of $83-88 \%$ for the diagnosis of iron deficiency. ${ }^{6} 816^{19-21}$ Although we cannot exclude the possibility that our use of serum ferritin values as a marker for iron deficiency may have had some influence on the results of this study, we believe the test to be sufficiently informative to support our conclusions. 
In previous cross sectional studies anaemic patients-particularly those with anaemia of chronic disease, but to a lesser extent also iron depleted anaemic patients-showed greater disease activity than non-anaemic patients, as measured by erythrocyte sedimentation rate and $\mathrm{C}$ reactive protein concentrations. ${ }^{12-14}$ The present study did not monitor current disease activity in the patients with RA. However, it was observed that those with anaemia of chronic disease, and the iron deficient patients who also showed anaemia of chronic disease, showed more features of a severe course of disease than did nonanaemic patients. These data indicate that the more severe course of disease observed in iron depleted anaemic patients may be attributed to the overlap with anaemia of chronic disease.

Our finding, in the present study, of a considerable overlap between anaemia of chronic disease and iron deficiency anaemia, leads to the question of how iron deficiency and chronic disease may be related in the development of anaemia. Each factor exerts different effects on iron metabolism. Chronic disease is associated with iron retention and decreased utilisation of iron as a result of block of the release of iron from the reticuloendothelial system, leading to anaemia. ${ }^{10} 11 \quad 15 \quad 22-24$ A negative iron balance first leads to depletion of iron stores, followed by a decrease in serum iron in addition, and finally the development of anaemia. ${ }^{7}$ In large population studies, depleted iron stores were found in $21-45 \%$ and anaemia in $2 \cdot 3-7 \cdot 7 \%$ of all healthy women. ${ }^{25-28}$ In the present study, iron stores were assessed in anaemic patients only. Iron deficiency was diagnosed in $48 \%$ of the anaemic women patients with $\mathrm{RA}$. It seems unlikely that patients with RA but no anaemia would have iron deficiency more often than anaemic patients with $\mathrm{RA}$, and one can assume, therefore, that the prevalence of iron deficiency in all women patients with RA does not exceed $48 \%$, which would be comparable to that in non-rheumatic populations. In contrast, iron deficiency anaemia was observed in $17 \%$ of all women patients with $\mathrm{RA}$, which appears to be more frequent than the norm. The relationship between iron deficiency and anaemia thus seems to be different in patients with RA, compared with non-rheumatic populations. This can perhaps be explained by the role of the chronic disease. Even in patients with iron deficiency anaemia, chronic disease may have contributed to the development of anaemia. Such a hypothesis gains support from our observation that both patients with iron deficiency anaemia, and those with anaemia of chronic disease, developed anaemia at a similar period in their follow up. In this view, chronic disease would superimpose decreased erythropoiesis and iron retention in patients with a pre-existing iron deficiency that did not by itself lead to anaemia. This hypothesis requires substantiation in further research investigating the influence of disease activity on iron deficiency anaemia.
In summary, anaemia appeared as a frequent and dynamic manifestation in this longitudinal study of patients with recent onset RA. It occurred rapidly after the onset of the symptoms of arthritis. Recovery and recurrence of anaemia were observed throughout follow up, leading to a longstanding and relatively high prevalence of anaemia in the population studied. Iron deficiency was diagnosed frequently in anaemic patients, but follow up revealed a considerable overlap with anaemia of chronic disease. The majority of cases of anaemia thus merit classification as anaemia of chronic disease. With the exception of demographic status, relatively few differences were observed between patients who were iron deficient and those with anaemia of chronic disease, although the latter group, particularly those with anaemia of chronic disease, were characterised by a more severe course of their RA than patients without anaemia.

The authors wish to express their gratitude to W L J van Putten statistician, for his assistance in analysing the data. This study was made possible by a grant from the Dutch League agains Rheumatism ('Het Nationaal Rheuma Fonds').

1 Hansen N E. The anaemia of chronic disorders: a bag of unsolved questions. Scand $\mathcal{f}$ Haematol 1983; 31: unsolved

2 Vreugdenhil G, Wognum A W, Van Eijk H G, Swaak A J. Anaemia in rheumatoid arthritis: the role of iron, vitamin $\mathrm{B} 12$, and folic acid deficiency, and erythropoietin responsiveness. Ann Rheum Dis 1990; 49: 93-8.

3 Baer A N, Dessypris E N, Krantz S B. The pathogenesis of anemia in rheumatoid arthritis: a clinical and laboratory analysis [Review]. Semin Arthritis Rheum 1990; 19: 209-23.

4 Smith R J, Davis P, Thomson A B R, Wadsworth L D, Fackre $P$. Serum ferritin levels in the anaemia of theumatoid arthritis. $\mathcal{F}$ Reumatol 1977; 4: 389-2.

5 Rajapakse C N A, Holt P J L, Perera B. Diagnosis of true iron deficiency in theumatoid arthritis. Ann Rheum Dis 1980; 39: 596-610.

6 Blake D R, Waterworth R F, Bacon P A. Assessment of iron stores in inflammation by assay of serum ferritin concentrations. $B M F$ 1981; 283: 1147-8.

7 Cook J D. Clinical evaluation of iron deficiency [Review]. Semin Hematol 1982; 19: 6-18.

8 Hansen T M, Hansen N E. Serum ferritin as indicator of iron responsive anaemia in patients with rheumatoid arthritis. Ann Rheum Dis 1986; 45: 596-602.

9 Vreugdenhil G, Baltus J A, Van Eijk H G, Swak A J. Prediction and evaluation of the effect of iron treatment in anaemic RA patients. Clin Rheumatol 1989; 8: ment in

10 Means R T, Krantz S B. Progress in understanding the pathogenesis of anemia of chronic disease. Blood 1992; 7 1639-47.

11 Krantz S B. Pathogenesis and treatment of the anemia of chronic disease [Review]. Am f Med Sci 1994; 307 353-9.

12 Vreugdenhil G, Lowenberg B, Van Eijk H G, Swaak A J G. Tumor necrosis factor alpha is associated with disease activity and degree of anaemia in patients with rheumatoid arthritis. Eur $\mathcal{F}$ Clin Invest 1992; 22: 488-93.

13 Cartwright G E, Lee G R. The anaemia of chronic disorders. Br $\mathcal{F}$ Haematol 1971; 21: 147-52.

14 Birgegard G, Hällgren R, Caro J. Serum erythropoietin in rheumatoid arthritis and other inflammatory arthritides. Relationship to anaemia and the effect of antiinflammatory treatment. $\mathrm{Br} f$ Haematol 1987 ; 65: inflammator

15 Weber J, Werre J M, Julius H W, Marx J J. Decreased iron absorption in patients with active rheumatoid arthritis, with and without iron deficiency. Ann Rheum Dis 1988; 47: 404-9.

16 Vreugdenhil G, Baltus C A, Van Eijk H G, Swaak A J. Anaemia of chronic disease: diagnostic significance of erythrocyte and serological parameters in iron deficient rheumatoid arthritis patients. Br $\mathcal{F}$ Rheumatol 1990; 29: 105-10.

17 Arnett F C, Edworthy S M, Bloch D A, et al. The American Rheumatism Association 1987 revised criteria for the Rheumatism Association 1987 revised criteria for the
classification of rheumatoid arthritis. Arthritis Rheum 1988; 31: 315-24.

18 Remacha A F, Rodrigues-de la Serna A, Garcia-Die F, Geli C, Gimferrer E. Erythroid abnormalities in rheumatoid arthritis: the role of erythropoietin. $\mathcal{F}$ Rheumatol 1992 19: 1687-91.

19 Zoli A, Altomonte L, Mirone L, et al. Serum transferrin receptors in rheumatoid arthritis. Ann Rheum Dis 1994; 53: 699-701. 
20 Porter D R, Sturrock R D, Capell H A. The use of serum ferritin estimation in the investigation of anaemia in patients with rheumatoid arthritis. Clin Exp Rheumatol 1994; 12: $179-82$.

21 Nielsen O J, Smedegaard Andersen L, Ludwigsen E, et al. Anaemia of rheumatoid arthritis: serum erythropoietin concentrations and red cell distribution width in relation to iron status. Ann Rheum Dis 1990; 49: 349-53.

22 Lee G R. The anaemia of chronic disease. Semin Hematol 1983; 20: 61-6.

23 Kent S, Weinberg E D, Stuart-Macadam P. The etiology of the anaemia of chronic disease and infections. $f$ Clin Epidemiol 1994; 47: 23-33.

24 Vreugdenhil G, Kroos M J, Van Eijk H G, Lowenberg B, Swaak A J. Impaired iron uptake and transferrin binding by erythroblasts in the anaemia of rheumatoid arthritis. Br f Rheumatol 1990; 29: 335-9.

25 Tibblin E, Bengtsson C, Hallberg L, Lennartsson J Haemoglobin concentration and peripheral blood cell counts in women. The population study of women in Scand f Haematol 1979; 22: 5-16.

26 Cook J D, Skikne B S, Lynch S R, Reusser M E. Estimate of iron sufficiency in the US population. Blood 1986; 68: $726-31$

27 Milman N, Kirchhoff M. Iron stores in 1359, 30- to 60 -year-old Danish women: evaluation by serum ferritin and haemoglobin. Ann Hematol 1992; 64: 22-7.

28 Rybo E, Bengtsson C, Hallberg L. Iron status of 38-year-old women in Gothenburg, Sweden. Scand 7 Haematol 1985; 34 (suppl 43): 41-55. 